\title{
Effects of leptin on intake of specific micro- and macronutrients in a woman with leptin gene deficiency studied off and on leptin at stable body weight
}

\author{
Julio Licinio ${ }^{\mathrm{a}, \mathrm{i}, *}$, Michael Milane ${ }^{\mathrm{b}}$, Sarika Thakur ${ }^{\mathrm{b}}$, Fiona Whelan ${ }^{\mathrm{b}}$, Bulent O. Yildiz ${ }^{\mathrm{c}}$ \\ Tuncay Delibasi ${ }^{\mathrm{d}}$, Patricia B. de Miranda ${ }^{\mathrm{e}}$, Metin Ozata ${ }^{\mathrm{f}}$, Erol Bolu ${ }^{\mathrm{g}}$, \\ Alex DePaoli ${ }^{\mathrm{h}}$, Ma-Li Wong ${ }^{\mathrm{a}}$ \\ ${ }^{a}$ Department of Psychiatry \& Behavioral Sciences (D-28), University of Miami, Miller School of Medicine, \\ 1695 NW 9th Avenue, Suite 3100, Miami, FL 33136, USA \\ ${ }^{\mathrm{b}}$ Semel Institute for Neuroscience and Human Behavior, David Geffen School of Medicine at UCLA, Los Angeles, 90095-1761 CA, USA \\ ${ }^{\mathrm{c}}$ Hacettepe University School of Medicine, Department of Internal Medicine Endocrinology and Metabolism Unit Hacettepe, 06100 Ankara, Turkey \\ ${ }^{\mathrm{d}}$ Department of Endocrinology and Metabolism, Ankara Numune Training and Research Hospital, Ankara 06100 Turkey \\ ${ }^{\mathrm{e}}$ General Clinical Research Center, David Geffen School of Medicine at UCLA, Los Angeles 90095-1761, USA \\ ${ }^{\mathrm{f}}$ Department of Endocrinology and Metabolism, Gulhane Haydarpasa Training Hospital, Acibadem-Istanbul 34660 Turkey \\ ${ }^{\mathrm{g}}$ Department of Endocrinology and Metabolism, Gulhane School of Medicine, Etlik-Ankara 06018, Turkey \\ ${ }^{\mathrm{h}}$ Amgen, Inc., Thousand Oaks, CA 91320, USA \\ ${ }^{\mathrm{i}}$ Federal University of Rio Grande do Sul (UFRGS), Porto Alegre 90400-060, Brazil
}

Received 14 September 2005; received in revised form 18 December 2005; accepted 1 February 2006

\begin{abstract}
In this report, we examine the effects of leptin on the intake of specific macro- and micronutrients in a female patient with leptin gene deficiency. The patient was studied off and on leptin at stable body weight, within the normal to mildly overweight range. The data were obtained by detailed dietary assessments, measuring dietary intakes by weighed food and fluid consumption records, and analyzed using nutrition analysis software. Overall, significant differences were found in the off versus on leptin treatment periods in the following categories: (i) macronutrients: kilocalories, protein, carbohydrates, monounsaturated fats, MFA 18:1 oleic and total fiber; (ii) vitamins: vitamin $\mathrm{C}$, pyridoxine and pantothenic acid; (iii) minerals: potassium, magnesium, copper and chromium; and amino acids: threonine, lysine and histidine. The nutritional data from this study indicates a direct link between the effects of leptin and ingestion of several specific micronutrients. The mechanisms underlying these effects warrant further investigation and study.
\end{abstract}

(C) 2007 Elsevier Ltd. All rights reserved.

Keywords: Leptin; Obesity; Micronutrients; Macronutrients; Vitamins; Minerals; Amino acids

\section{Introduction}

Obesity is a major public health problem worldwide. The US Surgeon General has stated that "Health problems resulting from overweight and obesity could reverse many of the health gains achieved in the US in recent decades." The prevalence is also increasing and needs urgent attention if

\footnotetext{
${ }^{*}$ Corresponding author.

E-mail address: licinio@miami.edu (J. Licinio).
}

the potential morbidity, mortality, and economic tolls that will be left in its wake are to be avoided (James, Leach, Kalamara, \& Shayeghi, 2001; Kuczmarski, Flegal, Campbell, \& Johnson, 1994; Roth, Qiang, Marban, Redelt, \& Lowell, 2004). The pathogenesis of obesity is far more complex than the simple paradigm of an imbalance between energy intake and energy output. Although this concept allows easy conceptualization of the various mechanisms involved in its development, obesity is an outcome that is much more than the mere result of excess eating and/or too 
little or lack of exercise (Campfield \& Smith, 1999; Friedman, 2000; Haslam \& James, 2005; Rosmond, 2004).

There is a vast network of hormones and brain circuits that regulate food intake and energy expenditure. Various types of knockout and transgenic animals have given us insight into the role of specific hormones and neurotransmitters on the regulation of body weight. However, due to species differences, such knowledge is not always applicable to humans. Our studies of a Turkish family with a leptin gene mutation have made it possible to clinically ascertain the specific effects of leptin deficiency in adults (Licinio et al., 2004; Ozata, Ozdemir, \& Licinio, 1999).

Leptin is the product of the $o b$ gene that was first identified as a hormone secreted by the white adipose tissue to signal satiety to the brain, and its levels in circulation are correlated with the degree of adiposity (Considine et al., 1996; Friedman \& Halaas, 1998; Prolo, Wong, \& Licinio, 1998; Zhang et al., 1994). Studies of defects in the leptin signaling pathway have elucidated mechanisms for obesity in animal models. A deficiency of leptin in both mice and human subjects is associated with massive obesity and hypogonadism (Farooqi et al., 1999, 2002; Licinio et al., 2004; Montague et al., 1997; Ozata et al., 1999; Strobel, Issad, Camoin, Ozata, \& Strosberg, 1998; Zhang et al., 1994). It has been demonstrated that chronic exogenous administration of leptin or over expression in transgenic mice reduces body fat by reducing food intake and increasing the catabolic activity of the sympathetic nervous system (Considine, 2005).

Unlike the $o b / o b$ mouse model in which leptin was first characterized, most humans who are obese are not leptindeficient but rather leptin resistant, and therefore have elevated circulating leptin levels. While most human obesity is polygenic, the recognition of monogenic variants has greatly enhanced our knowledge about the etiopathogenesis of obesity (Farooqi \& O'Rahilly, 2005; Licinio et al., 2004). In an extended Turkish family, we have identified four homozygous and more than eight adult individuals heterozygous for a functional mutation of the leptin gene (Ozata et al., 1999). This truncated leptin molecule is identical to that of the $o b / o b$ mouse.

We have successfully rescued the phenotype of morbid obesity and hypogonadism in this family by long-term leptin treatment. In the pilot study reported here, we studied the youngest adult female patient at stable body weight in the normal to mildly overweight range in a novel off and on leptin paradigm. This permitted for the first time in a human model the characterization of the impact of leptin on food intake as well as micro- and macronutrient choice, without the confounding variables of obesity or ongoing weight loss.

\section{Materials and methods}

\section{Leptin data}

The female patient for this study was recruited in Turkey, and treated at the National Center for Research
Resources-supported General Clinical Research Center (GCRC) at the University of California at Los Angeles, where the study took place under protocols approved by the Food and Drug Administration, the University of California at Los Angeles Institutional Review Boards and the Central Ethical Committee of the Turkish Ministry of Health. Consent was obtained and safe-guarded by an independent consent monitoring process, overseen by the UCLA IRB. The doses of r-metHuLeptin were designed to achieve a normal leptin concentration based on body fat of $30 \%$ in females and $20 \%$ in males (Licinio et al., 2004). We chose daily evening administration to model the normal circadian variation in endogenous leptin, which is characterized by a pulsatile circadian rhythm with marked nocturnal rise.

The results of overall leptin treatment were previously reported (Licinio et al., 2004). Briefly, this patient lost $46.3 \mathrm{~kg}$ in the first 14 months of leptin replacement treatment, going from a BMI of 44.7 to $24.9 \mathrm{~kg} / \mathrm{m}^{2}$ at the end of this period. She was studied in this off and on leptin protocol 19 months after achieving normal body weight, which corresponded to 33 months post-initiation of leptin replacement.

In this feasibility study, we withdrew leptin treatment under close medical supervision in the GCRC inpatient setting for 2 weeks and then replaced leptin again as previously administered $[0.2 \mathrm{mg} /$ day subcutaneously (sc) at $18 \mathrm{~h}]$. Nutritional data were extensively collected off and on leptin treatment and are reported here. After the off leptin period was completed, patient was restarted on her usual daily leptin dose of $0.2 \mathrm{mg} /$ day sc.

\section{Dietary assessment}

We measured dietary intake in this study by weighed food consumption records conducted by a Senior Dietician in the inpatient research setting. The patient was allowed to eat ad libitum, so that the effects of leptin on food intake and nutrient choice could be documented. Food records were collected at repeat intervals (off and on leptin treatment) by trained dietary staff at the GCRC as follows: (1) off leptin treatment period: 14 days total; food intake was measured for 6 days, starting one week after initiation of the off leptin period. (2) This was immediately followed by the on leptin period of 14 days total, with food intake measured for 7 days, starting one week after initiation of the on leptin period. Thus, the off and on leptin study periods were in blocks 1 week apart from each other.

All food and beverages provided to the study participant was recorded by weight (in grams, to nearest $0.1 \mathrm{~g}$ ) with a precision balance (Mettler-Toledo, Inc., Columbus, $\mathrm{OH}$ ). Actual intake was calculated by subtracting content of uneaten food and beverage items from initial content of each item served. Dietary records were carefully reviewed by the GCRC Senior Dietician for accuracy and proper tracking. Nutrient intake was calculated using a nutrition analysis software (Nutritionist Pro, First DataBank, Inc., 
San Bruno, CA), which bases its analysis on a comprehensive database of over 18,000 foods and ingredients that are updated annually.

\section{Physical activity and body composition}

Patient maintained a baseline level of physical activity in the context of an inpatient hospitalization in the off and on leptin periods reported here.

\section{Statistical analysis}

Means and standard errors were calculated for all nutritional variables within each category: off leptin treatment ( $n=6$ days), followed by the on leptin period $(n=7)$. To correct for multiple testing, the Bonferroni post hoc method of corrections was used to correct for false significance values. After correcting for multiple testing using the Bonferroni post hoc correction method, the adjusted cutoff significance level criteria were as follows: (i) percentage of kilocalories: $p=0.017$ ( $N=3$ tests); (ii) macronutrients: $p=0.003$ ( $N=15$ tests); (iii) vitamins: $p=0.003$ ( $N=15$ tests); (iv) minerals: $p=0.004(N=12$ tests); and (iv) amino acids: $p=0.005(N=11$ tests). All analyses were performed using SPSS version 13.0 (SPSS Inc, Chicago, IL).

\section{Results}

\section{Body weight and BMI}

Patient had a weight of $58.3 \mathrm{~kg}\left(\mathrm{BMI}=25.02 \mathrm{~kg} / \mathrm{m}^{2}\right)$ just before initiation of the off leptin period. At the end of the 14-day off leptin period, her weight increased to $60.7 \mathrm{~kg}$ $\left(B M I=26.05 \mathrm{~kg} / \mathrm{m}^{2}\right)$. The weight reached its peak 20 days after initiation of the off leptin period (this was 6 days after leptin replacement had resumed). That peak weight was $63.0 \mathrm{~kg}\left(27.03 \mathrm{~kg} / \mathrm{m}^{2}\right)$. The fact that her weight continued to rise for 6 days after leptin was re-started elegantly demonstrates that leptin does not control food intake acutely, but serves as a long-term satiety signal. Two days after the patient achieved peak weight and had already started to lose weight, we started nutritional assessment for the on leptin period. During that on leptin period her weight continued to drop: 14 days after re-initiation of leptin replacement, corresponding to the end of nutritional assessment period on leptin, her weight was $61.4 \mathrm{~kg}$ $\left(\mathrm{BMI}=26.35 \mathrm{~kg} / \mathrm{m}^{2}\right)$.

\section{Statistical analyses of nutritional data}

Treatment periods were compared using paired $t$-tests for the following nutritional categories: percent of kilocalories, macronutrients, vitamins, minerals, and amino acids. Specifically, we collected data and analyzed the following specific items in these categories:
Percentage of kilocalories: protein, carbohydrates and total fat.

Macronutrients: kilocalories, protein, carbohydrate, total fat, cholesterol, saturated fat, monounsaturated fat, polyunsaturated fat, MFA 18:1 oleic, PFA 18:2 linoleic, PFA 18:3 linolenic, PFA 20:5 EPA, PFA 22:6 DHA, total fiber and total sugar.

Vitamins: vitamin A, beta-carotene, vitamin C, vitamin $\mathrm{D}$, vitamin $\mathrm{E}$, alpha-tocopherol, thiamin, riboflavin, niacin, pyridoxine (Vitamin B6), folate, cobalamin (vitamin B12), biotin, pantothenic acid and vitamin K. Minerals: sodium, potassium, calcium, iron, phosphorus, magnesium, zinc, copper, manganese, selenium, chromium and molybdenum.

Amino acids: tryptophan, threonine, isoleucine, leucine, lysine, methionine, cystine, phenylalanine, tyrosine, valine and histidine.

\section{Effects of leptin on nutritional data}

Overall, significant differences were found off versus on leptin replacement treatment in all but one of the nutritional categories. We found the following significant differences between the off and on leptin period in specific categories:

Macronutrients (see Table 1): kilocalories $(p=0.001)$, protein $(p=0.003)$, carbohydrates $(p=0.001)$, monounsaturated fats $(p=0.001)$, MFA 18:1 oleic $(p=0.001)$ and total fiber $(p=0.0001)$ showed a significant difference off and on leptin treatment. Total sugar $(p=0.006)$ also exhibited a trend for significance after Bonferroni correction.

Vitamins (see Table 2): vitamin $\mathrm{C}(p=0.001)$, pyridoxine $(p=0.002)$ and pantothenic acid $(p=0.001)$. Also within the vitamin category, there was a trend towards significance for folate post-Bonferroni correction $(p=0.006)$.

Minerals (see Table 3): potassium $(p=0.0001)$, magnesium $(p=0.001)$, copper $(p=0.0001)$ and chromium $(p=0.002)$. There was also a trend towards significance with zinc $(p=0.005)$.

Amino acids (see Table 4): threonine $(p=0.004)$, lysine $(p=0.005)$ and histidine $(p=0.005)$. Tryptophan, methionine and cystine (all with $p=0.006$ ) exhibited a trend toward statically significant differences postBonferroni correction.

$p$-Values per variable within each main category are represented in Tables $1-4$, and the statistically significant variables post-correction are boldfaced in the tables.

\section{Discussion}

In comparison with the on leptin period, we show in the off leptin period that several changes in macronutrient intake occur: the ingestion of total fat decreased by $17.6 \%$, 
Table 1

$p$-Values per variables within the percentage of kilocalories and macronutrient categories affected by leptin replacement

\begin{tabular}{|c|c|c|c|c|c|c|c|c|c|}
\hline \multirow[t]{2}{*}{ Macro- and micronutrients } & \multicolumn{2}{|c|}{ Off leptin } & \multicolumn{2}{|c|}{ On leptin } & \multirow[t]{2}{*}{$p$-Value } & \multirow[t]{2}{*}{ Mean difference } & \multirow[t]{2}{*}{ Std. error difference } & \multicolumn{2}{|c|}{$95 \%$ confidence interval } \\
\hline & Mean & SEM & Mean & SEM & & & & Lower & Upper \\
\hline \multicolumn{10}{|l|}{ Percentage of kilocalories } \\
\hline Protein $(\%)$ & 16.58 & 1.06 & 15.79 & 0.55 & 0.50 & 0.80 & 1.14 & -1.72 & 3.31 \\
\hline Fat $(\%)$ & 55.58 & 1.37 & 53.83 & 1.43 & 0.40 & 1.75 & 1.99 & -2.63 & 6.14 \\
\hline Carbohydrate (\%) & 27.83 & 0.49 & 30.47 & 1.35 & 0.11 & -2.64 & 1.54 & -6.02 & 0.75 \\
\hline \multicolumn{10}{|l|}{ Macronutrients } \\
\hline Kilocalories (Kcal) & 3316.10 & 179.88 & 2493.68 & 79.55 & 0.001 & 822.42 & 186.53 & 411.87 & 1232.97 \\
\hline Protein $(\mathrm{g})$ & 139.41 & 10.43 & 99.67 & 4.02 & 0.003 & 39.74 & 10.53 & 16.55 & 62.92 \\
\hline Carbohydrate (g) & 468.59 & 28.58 & 339.89 & 12.13 & 0.001 & 128.69 & 29.38 & 64.02 & 193.37 \\
\hline Total fat $(\mathrm{g})$ & 104.28 & 6.22 & 85.95 & 5.46 & 0.048 & 18.34 & 8.24 & 0.20 & 36.47 \\
\hline Cholesterol (mg) & 770.77 & 32.98 & 620.54 & 67.37 & 0.085 & 150.24 & 79.26 & -24.22 & 324.70 \\
\hline Saturated fat (g) & 39.48 & 3.13 & 34.53 & 3.65 & 0.334 & 4.95 & 4.90 & -5.84 & 15.75 \\
\hline Monounsaturated fat (g) & 36.50 & 1.95 & 23.87 & 2.20 & 0.001 & 12.64 & 2.99 & 6.06 & 19.22 \\
\hline Polyunsaturated fat $(\mathrm{g})$ & 15.38 & 1.79 & 11.27 & 2.43 & 0.213 & 4.11 & 3.11 & -2.73 & 10.96 \\
\hline MFA $18: 1$ oleic $(\mathrm{g})$ & 28.36 & 1.18 & 18.83 & 1.78 & 0.001 & 9.54 & 2.22 & 4.64 & 14.43 \\
\hline PFA 18:2 linoleic (g) & 12.40 & 1.59 & 9.00 & 2.10 & 0.235 & 3.40 & 2.71 & -2.56 & 9.36 \\
\hline PFA 18:3 linolenic $(\mathrm{g})$ & 1.26 & 0.26 & 1.17 & 0.25 & 0.807 & 0.09 & 0.37 & -0.72 & 0.90 \\
\hline PFA 20:5 EPA (g) & 0.03 & 0.00 & 0.01 & 0.00 & 0.035 & 0.01 & 0.00 & 0.00 & 0.02 \\
\hline PFA 22:6 DHA (g) & 0.10 & 0.01 & 0.07 & 0.01 & 0.014 & 0.04 & 0.01 & 0.01 & 0.06 \\
\hline Total fiber (g) & 28.83 & 0.72 & 22.74 & 0.78 & 0.000 & 6.09 & 1.07 & 3.73 & 8.45 \\
\hline Total sugar $(\mathrm{g})$ & 254.69 & 21.50 & 175.89 & 11.28 & 0.006 & 78.81 & 23.25 & 27.64 & 129.97 \\
\hline
\end{tabular}

The significance level $(\mathrm{SL})$ of the $p$-value is as follows for the specific category: percentage of kilocalories $(\mathrm{SL}=0.017)$, macronutrients $(\mathrm{SL}=0.003)$. Values that are significant post-Bonferroni corrections are given in bold type.

Table 2

$p$-Values per variables within the vitamin category affected by leptin replacement

\begin{tabular}{|c|c|c|c|c|c|c|c|c|c|}
\hline \multirow[t]{2}{*}{ Macro- and micronutrients } & \multicolumn{2}{|c|}{ Off leptin } & \multicolumn{2}{|c|}{ On Leptin } & \multirow[t]{2}{*}{$p$-Value } & \multirow[t]{2}{*}{ Mean difference } & \multirow[t]{2}{*}{ Std. error difference } & \multicolumn{2}{|c|}{$95 \%$ confidence interval } \\
\hline & Mean & SEM & Mean & SEM & & & & Lower & Upper \\
\hline \multicolumn{10}{|l|}{ Vitamins } \\
\hline Vitamin A (IU) & 1662.58 & 49.99 & 1719.58 & 122.55 & 0.0694 & -57.00 & 140.92 & -367.17 & 253.16 \\
\hline Beta-carotene $(\mu \mathrm{g})$ & 3652.88 & 469.30 & 3818.35 & 502.51 & 0.816 & -165.47 & 695.95 & -1697.25 & 1366.31 \\
\hline Vitamin C (mg) & 382.79 & 31.76 & 218.82 & 20.45 & 0.001 & 163.97 & 36.69 & 83.22 & 244.72 \\
\hline Vitamin D (IU) & 5.68 & 0.74 & 4.62 & 0.36 & 0.209 & 1.05 & 0.79 & -0.68 & 2.79 \\
\hline Vitamin E (mg) & 7.24 & 0.85 & 5.89 & 0.62 & 0.217 & 1.35 & 1.03 & -0.92 & 3.62 \\
\hline Alpha tocopherol (mg) & 4.32 & 0.30 & 3.61 & 0.35 & 0.163 & 0.71 & 0.47 & -0.33 & 1.75 \\
\hline Thiamine (mg) & 1.77 & 0.07 & 1.41 & 0.08 & 0.007 & 0.36 & 0.11 & 0.12 & 0.60 \\
\hline Riboflavin (mg) & 3.47 & 0.24 & 2.81 & 0.17 & 0.040 & 0.66 & 0.28 & 0.04 & 1.28 \\
\hline Niacin (mg) & 30.47 & 1.58 & 20.02 & 2.63 & 0.008 & 10.45 & 3.21 & 3.39 & 17.52 \\
\hline Pyridoxine (mg) & 3.60 & 0.12 & 2.72 & 0.17 & 0.002 & 0.88 & 0.21 & 0.40 & 1.35 \\
\hline Folate $(\mu \mathrm{g})$ & 548.06 & 14.40 & 467.99 & 18.11 & 0.006 & 80.08 & 23.72 & 27.86 & 132.29 \\
\hline Cobalamin $(\mu \mathrm{g})$ & 7.32 & 0.81 & 5.49 & 0.48 & 0.069 & 1.83 & 0.91 & -0.17 & 3.83 \\
\hline Biotin $(\mu \mathrm{g})$ & 52.07 & 3.08 & 42.47 & 3.90 & 0.086 & 9.60 & 5.10 & -1.62 & 20.83 \\
\hline Pantothenic acid (mg) & 8.62 & 0.37 & 6.44 & 0.31 & 0.001 & 2.18 & 0.48 & 1.13 & 3.24 \\
\hline Vitamin $\mathrm{K}(\mu \mathrm{g})$ & 29.92 & 7.27 & 27.15 & 7.30 & 0.795 & 2.76 & 10.37 & -20.06 & 25.58 \\
\hline
\end{tabular}

The significance level (SL) of the $p$-value is as follows for the specific category: vitamins $(\mathrm{SL}=0.003)$. Values that are significant post-Bonferroni corrections are given in bold type.

the intake of carbohydrates decreased by $27.5 \%$, and protein intake decreased by $28.5 \%$. The overall proportion of fat, carbohydrate and protein in the daily diet did not change in the off leptin state (see Table 1). Additionally, we report that in the off leptin period there were statistically significant increases in the intake of the specific micronutrients: vitamin $\mathrm{C}$, pyridoxine, pantothenic acid, folate, potassium, magnesium, copper, chromium, threonine, lysine, histidine, tryptophan, methionine and cystine (see Tables 2-4).

Various studies have shown that the extreme obesity of the obese (ob/ob) mouse is attributable to mutations in the gene encoding leptin, which is an adipocyte-specific secreted protein with profound effects on appetite and 
Table 3

p-Values per variables within the minerals category affected by leptin replacement

\begin{tabular}{|c|c|c|c|c|c|c|c|c|c|}
\hline \multirow[t]{2}{*}{ Macro- and micronutrients } & \multicolumn{2}{|c|}{ Off leptin } & \multicolumn{2}{|c|}{ On leptin } & \multirow[t]{2}{*}{$p$-Value } & \multirow[t]{2}{*}{ Mean difference } & \multirow[t]{2}{*}{ Std. error difference } & \multicolumn{2}{|c|}{$95 \%$ confidence interval } \\
\hline & Mean & SEM & Mean & SEM & & & & Lower & Upper \\
\hline \multicolumn{10}{|l|}{ Minerals } \\
\hline Sodium (mg) & 3348.74 & 362.48 & 3140.18 & 235.65 & 0.629 & 208.56 & 420.17 & -716.23 & 1133.35 \\
\hline Potassium (mg) & 5250.63 & 188.39 & 3832.83 & 178.04 & 0.000 & 1417.80 & 259.66 & 846.30 & 1989.30 \\
\hline Calcium (mg) & 1156.89 & 137.03 & 1131.05 & 87.59 & 0.873 & 25.84 & 157.85 & -321.59 & 373.28 \\
\hline Iron $(\mathrm{mg})$ & 20.60 & 0.97 & 15.99 & 1.38 & 0.023 & 4.61 & 1.75 & 0.77 & 8.46 \\
\hline Phosphorus (mg) & 1898.23 & 143.09 & 1424.33 & 97.32 & 0.017 & 473.91 & 168.75 & 102.49 & 845.33 \\
\hline Magnesium (mg) & 365.56 & 14.47 & 280.29 & 10.60 & 0.001 & 85.27 & 17.59 & 46.54 & 123.99 \\
\hline Zinc (mg) & 11.91 & 1.16 & 7.81 & 0.46 & 0.005 & 4.10 & 1.18 & 1.51 & 6.69 \\
\hline Copper (mg) & 1.24 & 0.05 & 0.91 & 0.04 & 0.000 & 0.33 & 0.06 & 0.19 & 0.46 \\
\hline Manganese (mg) & 2.81 & 0.19 & 2.75 & 0.20 & 0.836 & 0.06 & 0.28 & -0.56 & 0.68 \\
\hline Selenium $(\mu \mathrm{g})$ & 140.04 & 11.98 & 101.33 & 6.16 & 0.012 & 38.71 & 12.88 & 10.35 & 67.06 \\
\hline Chromium (mg) & 0.05 & 0.00 & 0.03 & 0.00 & 0.002 & 0.02 & 0.00 & 0.01 & 0.02 \\
\hline Molybdenum $(\mu \mathrm{g})$ & 28.23 & 6.04 & 20.93 & 2.11 & 0.249 & 7.30 & 6.00 & -5.91 & 20.51 \\
\hline
\end{tabular}

The significance level (SL) of the $p$-value is as follows for the specific category: minerals $(\mathrm{SL}=0.004)$. Values that are significant post-Bonferroni corrections are given in bold type.

Table 4

$p$-Values per variables within the amino acid category affected by leptin replacement

\begin{tabular}{|c|c|c|c|c|c|c|c|c|c|}
\hline \multirow[t]{2}{*}{ Macro- and micronutrients } & \multicolumn{2}{|l|}{ Off leptin } & \multicolumn{2}{|c|}{ On leptin } & \multirow[t]{2}{*}{$p$-Value } & \multirow[t]{2}{*}{ Mean difference } & \multirow[t]{2}{*}{ Std. error difference } & \multicolumn{2}{|c|}{$95 \%$ confidence interval } \\
\hline & Mean & SEM & Mean & SEM & & & & Lower & Upper \\
\hline Tryptophan (mg) & 1379.51 & 133.22 & 925.83 & 51.01 & 0.006 & 453.68 & 134.38 & 157.92 & 749.44 \\
\hline Threonine (mg) & 4929.33 & 460.67 & 3234.94 & 181.13 & 0.004 & 1694.39 & 466.82 & 666.93 & 2721.84 \\
\hline Isoleucine (mg) & 6198.82 & 623.28 & 4184.62 & 232.88 & 0.008 & 2014.20 & 626.12 & 636.12 & 3392.28 \\
\hline Methionine (mg) & 3133.13 & 311.77 & 2063.77 & 114.85 & 0.006 & 1069.36 & 312.47 & 381.61 & 1757.10 \\
\hline Cystine (mg) & 1924.91 & 179.97 & 1307.95 & 66.75 & 0.006 & 616.96 & 180.57 & 219.52 & 1014.39 \\
\hline Phenylalanine (mg) & 5687.89 & 585.97 & 3882.62 & 219.45 & 0.011 & 1805.28 & 588.86 & 509.20 & 3101.36 \\
\hline Tyrosine (mg) & 4673.49 & 547.35 & 3183.21 & 205.75 & 0.020 & 1490.29 & 550.39 & 278.89 & 2701.69 \\
\hline Valine (mg) & 6692.74 & 673.34 & 4569.01 & 251.34 & 0.009 & 2123.74 & 676.31 & 635.19 & 3612.28 \\
\hline Histidine (mg) & 3643.94 & 353.34 & 2402.78 & 135.98 & 0.005 & 1241.16 & 356.72 & 456.04 & 2026.29 \\
\hline
\end{tabular}

The significance level (SL) of the $p$-value is as follows for the specific category: amino acids $(\mathrm{SL}=0.005)$. Values that are significant post-Bonferroni corrections are given in bold type.

energy expenditure. Clinical research studies of leptin gene mutations have demonstrated severe obesity in congenital leptin deficiency, which is reversed with leptin treatment (Farooqi et al., 1999, 2002; Licinio et al., 2004; Montague et al., 1997). These findings support the conclusion that leptin is an important regulator of energy balance in humans.

In a 4-year study of congenitally deficient, morbidly obese children treated with daily dose of recombinant human leptin, there was compelling evidence that the subcutaneous administration of recombinant human leptin has major and sustained beneficial effects on the multiple phenotypic abnormalities associated with congenital human leptin deficiency. This included beneficial effects on appetite, fat mass, hyperinsulinemia, hyperlipidemia, plasma thyroid hormone levels, cytokine production and release, circulating $\mathrm{CD} 4(+) \mathrm{T}$ cells and T-cell proliferation (Farooqi et al., 1999, 2002).

In a recent study, we reported the effects of leptin therapy in three leptin-deficient adults, including the one reported here (Williamson et al., 2005). There were key differences between that study and the data presented here. First, that study provided a microanalysis of changes in eating behavior and rating of hunger and satiety, but macro- and micronutrient intake was not examined. Importantly, that study was conducted during the onset of leptin treatment when subjects were morbidly obese and losing weight, while we report the effects of withdrawal of leptin after the subject was stable at a normal weight.

In conclusion, we report that even brief discontinuation of leptin therapy results in marked weight gain, reaching an $8.1 \%$ increase in total body weight, and significant changes 
in micro- and macronutrient intake. This is to our knowledge the first report of the specific effects of leptin on micronutrient intake in humans. The implications of these results are several-fold. Because our leptin-deficient subject has been maintained at very low doses of leptin $(0.2 \mathrm{mg} /$ day $)$, it had been unclear if continuous leptin treatment is required. The data presented here indicate that even a short leptin-free period profoundly affects food intake and nutrient ingestion in leptin-deficient patients. Therefore, long-term, and possibly lifelong, replacement treatment will be required. On the other hand, we show that in the context of a well-supervised research inpatient setting, it is possible to conduct studies that compare and contrast at a normal to mildly overweight range of body weight the off and on leptin states. This opens up a new avenue for research on the effects of human leptin. Such studies are made possible by these rare but highly informative cases of leptin deficiency.

Previous reports of leptin deficiency have been restricted mostly to children who are still in a growth phase. These studies have not included detailed data on the nutritional effects of withdrawing leptin treatment in the context of normal and chronically stable body weight. The fact that our patient was an adult with stable weight in response to a fixed low dose regimen of leptin replacement gives us the unique opportunity to ascertain the effects of leptin on nutrition by comparing data from the treated (on) and the non-treated (off) states.

Our results provide further support for the hypothesis that the human leptin pathway is crucial for the regulation of food intake and body weight, and that non-monogenic types of obesity are characterized by a state of leptin resistance. Pharmacological attempts to overcome leptin resistance (Wang, Orci, Ravazzola, \& Unger, 2005) may have a promise in the experimental treatment of obesity in the future.

\section{Acknowledgments}

The authors have been supported by NIH grants DK58851, DK063240, RR16996, RR017365, RR000865, HL04526, MH062777, and HG002500, and by an award from the Dana Foundation.

\section{References}

Campfield, L. A., \& Smith, F. J. (1999). The pathogenesis of obesity. Baillieres Best Practice and Research Clinical Endocrinology and Metabolism, 13, 13-30.

Considine, R. V. (2005). Human leptin: An adipocyte hormone with weight-regulatory and endocrine functions. Seminars in Vascular Medicine, 5, 15-24.

Considine, R. V., Sinha, M. K., Heiman, M. L., Kriauciunas, A., Stephens, T. W., Nyce, M. R., et al. (1996). Serum immunoreactive leptin concentrations in normal-weight and obese humans. The New England Journal of Medicine, 334, 292-295.

Farooqi, I. S., Jebb, S. A., Langmack, G., Lawrence, E., Cheetham, C. H., Prentice, A. M., et al. (1999). Effects of recombinant leptin therapy in a child with congenital leptin deficiency. The New England Journal of Medicine, 341, 879-884.

Farooqi, I. S., Matarese, G., Lord, G. M., Keogh, J. M., Lawrence, E., Agwu, C., et al. (2002). Beneficial effects of leptin on obesity, T cell hyporesponsiveness, and neuroendocrine/metabolic dysfunction of human congenital leptin deficiency. Journal of Clinical Investigation, 110, 1093-1103.

Farooqi, I. S., \& O'Rahilly, S. (2005). Monogenic obesity in humans. Annual Review of Medicine, 56, 443-458.

Friedman, J. M. (2000). Obesity in the new millennium. Nature, 404(6778), 632-634.

Friedman, J. M., \& Halaas, J. L. (1998). Leptin and the regulation of body weight in mammals. Nature, $395,763-770$.

Haslam, D. W., \& James, W. P. (2005). Obesity. Lancet, 366, 1197-1209.

James, P. T., Leach, R., Kalamara, E., \& Shayeghi, M. (2001). The worldwide obesity epidemic. Obesity Research, 9(Suppl. 4), $228 \mathrm{~S}-233 \mathrm{~S}$

Kuczmarski, R. J., Flegal, K. M., Campbell, S. M., \& Johnson, C. L. (1994). Increasing prevalence of overweight among US adults. The National Health and Nutrition Examination Surveys, 1960 to 1991. $J A M A, 272,205-211$.

Licinio, J., Caglayan, S., Ozata, M., Yildiz, B. O., de Miranda, P. B., O'Kirwan, F., et al. (2004). Phenotypic effects of leptin replacement on morbid obesity, diabetes mellitus, hypogonadism, and behavior in leptin-deficient adults. Proceedings of the National Academy of Sciences of the United States of America, 101, 4531-4536.

Montague, C. T., Farooqi, I. S., Whitehead, J. P., Soos, M. A., Rau, H., Wareham, N. J., et al. (1997). Congenital leptin deficiency is associated with severe early-onset obesity in humans. Nature, 387, 903-908.

Ozata, M., Ozdemir, I. C., \& Licinio, J. (1999). Human leptin deficiency caused by a missense mutation: Multiple endocrine defects, decreased sympathetic tone, and immune system dysfunction indicate new targets for leptin action, greater central than peripheral resistance to the effects of leptin, and spontaneous correction of leptin-mediated defects. Journal of Clinical Endocrinology and Metabolism, 84, 3686-3695.

Prolo, P., Wong, M. L., \& Licinio, J. (1998). Leptin. The International Journal of Biochemistry\& Cell Biology, 30, 1285-1290.

Rosmond, R. (2004). Aetiology of obesity: A striving after wind? Obesity Review, 5, 177-181.

Roth, J., Qiang, X., Marban, S. L., Redelt, H., \& Lowell, B. C. (2004). The obesity pandemic: Where have we been and where are we going? Obesity Research, 12(Suppl. 2), 88S-101S.

Strobel, A., Issad, T., Camoin, L., Ozata, M., \& Strosberg, A. D. (1998). A leptin missense mutation associated with hypogonadism and morbid obesity. Nat. Genet, 18, 213-215.

Wang, M. Y., Orci, L., Ravazzola, M., \& Unger, R. H. (2005). Fat storage in adipocytes requires inactivation of leptin's paracrine activity: Implications for treatment of human obesity. Proceedings of the National Academy of Sciences of the United States of America, December 2; [Epub ahead of print], doi:10.1073/pnas.0509001102.

Williamson, D. A., Ravussin, E., Wong, M. L., Wagner, A., Dipaoli, A., Caglayan, S., et al. (2005). Microanalysis of eating behavior of three leptin deficient adults treated with leptin therapy. Appetite, 45, $75-80$.

Zhang, Y., Proenca, R., Maffei, M., Barone, M., Leopold, L., \& Friedman, J. M. (1994). Positional cloning of the mouse obese gene and its human homologue. Nature, 372, 425-432. 